\title{
Influence of Cobalt (II) Chloride Catalysed on the Thermal and Optical Characterization of PEO Based Solid Polymer Electrolytes
}

\author{
Sharanappa Chapi and H. Devendrappa*
}

\author{
Department of Physics, Mangalore University, Mangalagangothri - 574 199, India
}

\begin{abstract}
Solution-casting technique was employed for the preparation of solid polymer electrolyte based polyethylene oxide (PEO) with $0,1,3$ and 5 weight percentage cobalt chloride $\left(\mathrm{CoCl}_{2}\right)$ films were characterized by X-ray Diffractometry (XRD), Differrential Scanning Calorimetry (DSC), Scanning Electron Microscope (SEM) and Ultra VioletVisible (UV-Vis.) Spectroscopy methods. The optical band gaps, absorption band edges and Urbach energy shows decrease with increasing of $\mathrm{Co}^{+2}$ ion concentration in the polymer matrix because of the formation of free radicals or cluster. The Thermogravimetry (TG) and Derivative Thermogravimetry (DTG) were used to examine the thermal stability of the film and it was found that the stability of the complexes is higher than that of the pure PEO due to the addition of $\mathrm{CoCl}_{2}$. The wavelength position of a fluorescence emission band varied by increasing of a dopant wt \% of salt.
\end{abstract}

Keywords: XRD, Optical band gaps, SEM, Fluorescence, Thermal stability.

\section{INTRODUCTION}

Solid polymer electrolytes (SPEs) has emerged as an important optical material in fabrication of optoelectronics device and promising photonic material for potential applications [1]. On structural, thermal, electrical, and optical properties of polymers have attracted much attention due to their applications in optical devices, solid-state batteries and other energy storage devices. The optical properties have been studied with the aim of achieving better reflection, antireflection, interference and polarization properties in modified polymer, the modification should depend upon the type of dopant and its chemical reactivity with the host matrix. The modified polymer may affect the induced optical absorption due to several reasons, namely, the polarization power of network formers, coordination numbers, concentration of non-bridging oxygen (oxygen ions having dangling bonds), as well as the presence of multivalent network forming and modifying ions [2-4].

The optical absorption can be comprehended mainly change in the shape of absorption and the shift of the absorption edge is very useful to understand the basic mechanism of inter band electron transition whenever material has been undergoes induced transitions between sub energy levels of existing band, which narrate information about the energy band structure. Although a number of works were devoted to the optical properties of doped polymer electrolyte films [5-16]. Moreover, polymers with high refractive index are very useful in optics and photonics due to their

*Address correspondence to this author at the Department of Physics, Mangalore University, Mangalagangothri - 574 199, India; Tel: (+91)-08242888707, Fax: (+91)-0824-2287289; E-mail: dehu2010@gmail.com ability to reduce reflection losses at interfaces, hence increase in the light output [17].

The investigation of the optical properties of polymer complexes is still limited and much experimental work is required in this direction. Polyethylene oxide (PEO) is an exceptional polymer; it dissolves high concentrations of a wide variety of salts to form polymer complexes. This paper is concerned with the optical properties of new polymer electrolytes based, cobalt chloride salt doped with a PEO. And thermal stability and degradation behaviors are useful to modify the polymer for newer applications. In view of all these, we have endeavored in this paper to study the morphology, structural, optical, fluorescence and thermal properties of the complexes films. These results may help the researchers toward applying these materials in optical communication and some optical device applications.

\section{EXPERIMENTAL METHODS}

\section{Materials Used and Polymer Film Preparation}

PEO from Sigma Aldrich Chemical Co. Ltd. (USA), (molecular weight of $5 \times 10^{6}$ ) was used as a host, cobalt chloride salt $\left(\mathrm{CoCl}_{2} \cdot 6 \mathrm{H}_{2} \mathrm{O}\right.$, anhydrous from Merck, India) was used as dopant and methanol $\left(\mathrm{CH}_{3} \mathrm{OH}\right)(\mathrm{AR}$, M.W.32) was used as a solvent for the preparation of solid polymer electrolyte films.

Pure and PEO doped films (PEO:CoCl $1000: 0,99: 1$, $97: 3$ and $95: 5 \%$ weight percentage, coded them as PEO, PCL1, PCL3 and PCL5) were prepared using solution casting method and their thickness of films is $0.29 \mathrm{~mm}$ [18]. In this process, the appropriate ratios of PEO and $\mathrm{CoCl}_{2}$ salt were dissolved in methanol and 
stirred at room temperature for $\sim 5$ hours to get a homogeneous solution. The solution was then poured into the polypropylene dishes and evaporated slowly at $303 \mathrm{~K}$. PEO films doped with mass fractions $0 \%, 1 \%$, $3 \%$ and $5 \%$ of $\mathrm{CoCl}_{2}$ were prepared. The dopant weight percentage concentration $\mathrm{W}(\mathrm{wt} \%)$ was calculated from the equation:

$W(w t \%)=\frac{w_{f}}{w_{p}+w_{f}} \times 100$

Where, $W_{p}$ and $W_{f}$ represent the weight of dopant and polymer, respectively. Further, viscous solution was poured into poly propylene dishes and allowed to evaporate slowly at room temperature to obtain freestanding. The films were dried in oven $40^{\circ} \mathrm{C}$ for 1 hour to remove residual solvent from films and stored in highly evacuated desiccators to avoid moisture absorption.

\section{Characterization Techniques}

The films were recorded the XRD patterns using the $\mathrm{Cu} \mathrm{Ka}(\lambda=1.54178 \AA)$ radiation from the Rigaku Miniflex 600-bench top X-ray diffractometer (Rigaku Americas 9009 New Trails Drive, The Woodlands Texas USA. 77381-5209) with scan speed of $1^{\circ}$ per minute and $2 \theta$ varied from 5 to $40^{\circ}$ with step size of 0.02. The UV-Vis. absorption data was recorded at room temperature using Lambda 35 UV-Vis (PerkinElmer, Waltham Massachusetts 02451, USA) Spectrophotometer in the wavelength region of 190$800 \mathrm{~nm}$. The thermal property was done by TGA-DTG (TGA Q500, TA instrument, New Castle, DE 19720, USA) under a nitrogen atmosphere with a heating rate of $10^{\circ} \mathrm{C} / \mathrm{min}$ from room temperature to $800{ }^{\circ} \mathrm{C}$ and Differential Scanning Calorimetry (DSC) (Model: Universal V4.5A TA instrument) is used to examine the glass transition temperature $(\mathrm{Tg})$ with $5^{\circ} \mathrm{C} /$ min heating rate with a nitrogen atmosphere and temperature range from -90 to $+120^{\circ} \mathrm{C}$. The mass of the sample was kept in 5-8mg and aluminium pans used to empty pan were weighed to a mass of $0.002 \mathrm{mg}$. The surface morphology of the films was characterized by SEM (JEOL Model JSM - 6390LV EDS Make JEOL Model JED - 2300, JEOL USA, Inc. in vacuum modes and specimen holder size is $10 \mathrm{~mm}$ diameter). Fluorescence measurement was taken with the help of Hitachi Fluorescence Spectrophotometer F-7000 (Hitachi High-Technologies Corporation, Japan) with a Xenon lamp as light source at exciting region of 200-220nm.

\section{RESULTS AND DISCUSSION}

\section{XRD Analysis}

Figure 1 shows the XRD patterns of PEO and doped polymer electrolytes and the calculated parameters are presented in Table 1. A sharp and intense diffraction peaks occur at $2 \theta=19.80^{\circ}$ and $24^{\circ}$ indicating the semi crystalline nature of PEO and subsequently for $5 \%$ wt of $\mathrm{CoCl}_{2}$ composition at $2 \theta$ $=19.19^{\circ}$ and $23.60^{\circ}$. The intensities of the peaks found decreases significantly upon the addition of salt may be due to an increase in the amorphous nature of the polymer. There is an appearance of new peaks at $2 \theta=30^{\circ}$ and $36^{\circ}$ for films with 5 wt $\% \mathrm{CoCl}_{2}$ showing the alteration in the material phase [19].

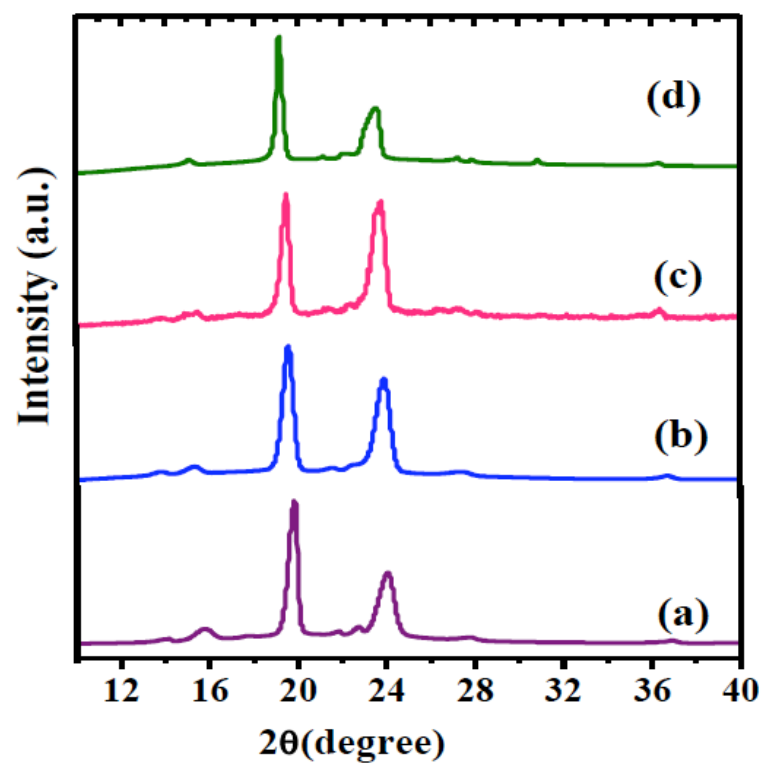

Figure 1: XRD pattern of polymer complexes at various wt $\%$ of $\mathrm{CoCl}_{2}$ (a) 0 ; (b) 1 ; (c) 3; (d) 5 .

These changes can be exactly correlated by means of chemical interaction between the oxygen of ether group and $\mathrm{Co}^{+}$ions [5]. The diffraction peaks tend to show variations in intensity as well as broadening for all doped films. It is interesting to note from figure that as the content of the $\mathrm{CoCl}_{2}$ is increased from 1 to $5 \mathrm{wt} \%$, the value of the full-width half maximum (FWHM) was found to decrease from 0.58 to $0.38\left(2 \theta=19^{\circ}\right)$ due to the effect of $\mathrm{CoCl}_{2}$. The average crystallite size $(\mathrm{L})$ was calculated using Scherer formula (Cullity and Stock, 2001)

$L=k \lambda / \beta \cos \theta$

where $\beta$ is the FWHM of the peak (in radian) $\lambda=$ $1.54178 \AA \mathrm{nm}$ is the wavelength of the $\mathrm{X}$-ray radiation 
used, and $k$ is the shape factor whose value is equal to 0.9 , assuming $k=0.9$ in the equation (2). The average inter-chain separation is calculated using the following equation (Alexander, 1969):

$\mathrm{R}=5 \lambda /(8 \sin \theta)$

The changes in the relative degree of crystallinity value of may be calculated as follows.

$X_{c}=\frac{A_{c}}{A_{c}+A_{a}} \times 100$

where $A_{c}$ and $A_{a}$ are the area of crystalline and amorphous region respectively. The variation in crystallite size $(L)$, average inter-chain separation $(R)$ and degree of crystallinity $\left(X_{c}\right)$ is shown in Table 1.

As increasing the doping concentration the $L, R$ and $X_{c}$ are observed decreases. These results are clearly noticed that decrease in the degree of crystallinity and increase the amorphous region. These results are well agreed with reported values that the decrease in crystalline is attributed to the degradation of the polymer chains (Shaheer Akhtar, 2010) and similar supportive confirmation from SEM and DSC results. Finally, XRD results suggesting an increase in the amorphous nature of the polymer matrix and decreasing of crystallinity.

Table 1: XRD Parameters of PEO and Doped PEO Polymer Electrolyte Films

\begin{tabular}{|c|c|c|c|c|c|c|}
\hline Sample & $\mathbf{2 \theta}$ & $\mathbf{d}(\mathbf{A})$ & $\mathbf{F W H M}(\boldsymbol{\beta})$ & $\mathbf{L}(\mathbf{n m})$ & $\mathbf{R}(\mathbf{A})$ & $\mathbf{X}_{\mathbf{c}} \%$ \\
\hline \hline PEO & 19.8 & 4.47 & 0.47 & 17.90 & 5.5 & 55.4 \\
\hline PCL1 & 19.6 & 4.52 & 0.58 & 14.46 & 5.6 & 51.8 \\
\hline PCL3 & 19.4 & 4.54 & 0.48 & 17.20 & 5.7 & 45.3 \\
\hline PCL5 & 19.2 & 4.62 & 0.38 & 21.72 & 5.8 \\
\hline
\end{tabular}

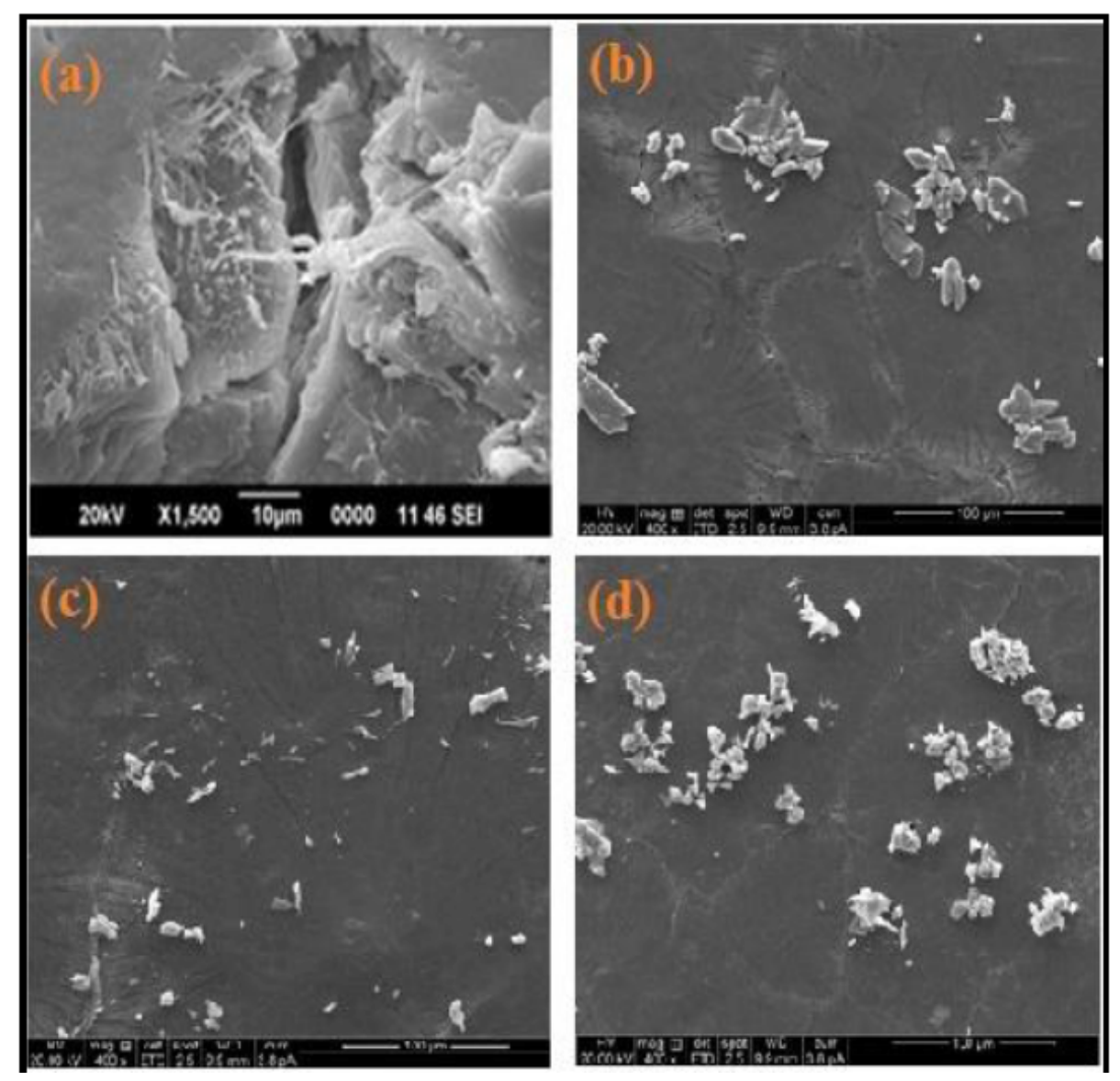

Figure 2: SEM photographs of polymer electrolytes at various wt\% of $\mathrm{CoCl}_{2}$ (a) 0 ; (b) 1 ; (c) 3 ; (d) 5 . 


\section{Morphology Study}

The scanning electron microscope (SEM) microphotographs of doped PEO films at different concentration are shown in Figure $\mathbf{2}(\mathbf{a}, \mathbf{b}, \mathbf{c} \& \mathbf{d})$. The surface morphology was significantly changed with the dopant represents compatibility between the polymer and dopant. The morphology of pure PEO in Figure 2a film shows a large spherulite with a rough surface as reported [20].

The doped films dispersed white spot shows on the spherulite surface and deep cracks with rough surface as shown in Figure $\mathbf{2 b}$. As the cobalt chloride content increases up to $3 \mathrm{wt} \%$; it is interesting to note that the population of white spots becomes increases as well as reduce their size; crack depth reduces as shown in Figure 2c. In the case of $5 w t \%$ Figure $\mathbf{2 d}$, the number of white spots increases, but their spherulite nature is not clearly visible subsequently surface becomes smooth compared to PCL1. These changes clearly suggest aggregation of the cobalt chloride in the host polymeric matrix. The SEM results well correlate with the obtained XRD, so finally conclude that the material undergoes a phase change from crystalline to amorphous is good agreed with the reported results [21-24].

\section{UV-Visible Absorption Study}

One of the most direct and simplest methods for probing the electron inter-intra band transition of materials can be by studying optical absorption. In the absorption process, a photon of known energy excites an electron from a lower energy state to a higher one. The optical relative parameters such as absorption edge, optical band gaps, activation energy and other parameters were estimated using this data [25]. The spectra of PEO and doped PEO with different cobalt chloride salt concentrations are shown in Figure 3 . In the UV region, maximum absorption is found at $194 \mathrm{~nm}$ for PEO has shifted to higher wavelength $245 \mathrm{~nm}$ (red shift) for $5 \%$ of $\mathrm{CoCl}_{2}$ [26] and the intensity of the bands also increases with the increasing $\mathrm{CoCl}_{2}$ content.

The optical absorption in the UV region exhibits a blue shift $685-645 \mathrm{~nm}$ which is characteristic of the octahedral structure $\mathrm{Co}^{2+}$ in the polymer matrix. The blue shift transition originates from the fact that the solvent molecules are oriented around the solute molecules to fit with the ground state charge distribution of the solute molecules. On excitation, if the charge distribution changed markedly $n \rightarrow \pi^{*}$ transitions, the solvent molecule would not have the position and orientation to bind with the excited state charge distribution. This absorption distortion is found to decrease gradually with increasing $\mathrm{CoCl}_{2}$ content which may provide proper tendency to local order in the amorphous polymer structure (El-Shahawy, 1993).

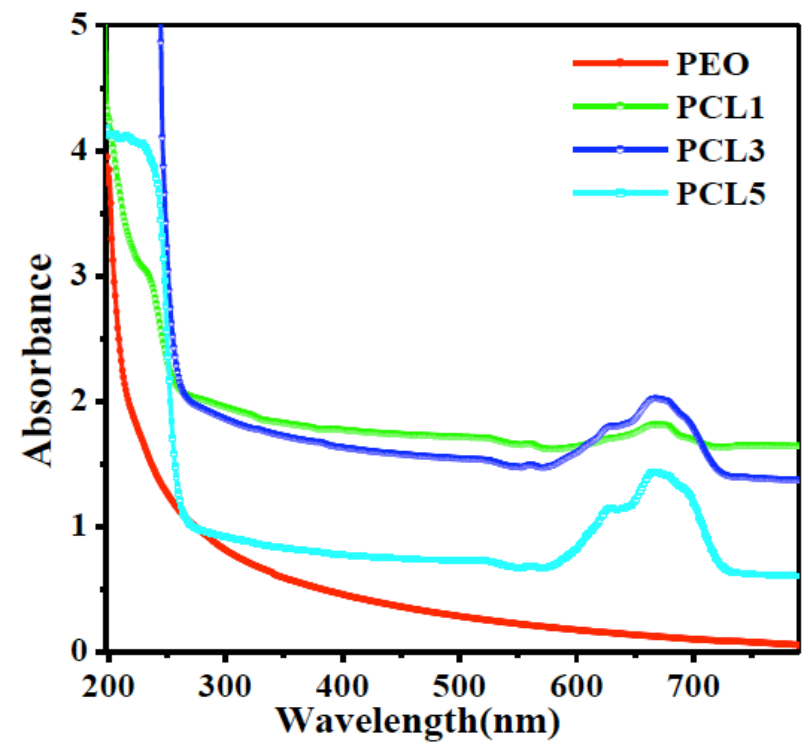

Figure 3: The absorption spectra of polymer electrolytes at various wt\% of $\mathrm{CoCl}_{2}$ (a) 0 ; (b) 1 ; (c) 3 ; (d) 5 .

Thus, the octahedron is expected to become more symmetric due to the contraction effect of the interactions. Another tail band observed in the range of $685-645 \mathrm{~nm}$ indicates the presence of $\mathrm{Co}^{2+}$ in proper coordination within the polymer matrix is good agreed with reported results by Nassar and Abbas (1981). The red shift absorption in the ultraviolet region and blue shift in the visible region sign of the creations of free radicals or ions as a result charge mobility is more significant, hence optical band gaps decrease conversely conductivity became high. Absorption is expressed in terms of the coefficient $\alpha(\omega)$, which is defined as the relative decrease rate in light intensity. The absorption coefficient $\alpha(\omega)$ was obtained from the absorbance (A). After correction for reflection $(\omega)$ can be calculated using Beer Lambert's formula:

$\mathrm{I}=\mathrm{I}_{0} \exp (-\alpha \mathrm{x})$

Thus,

$$
(\omega)=2.303 / x \log \left(I_{0} / \mathrm{I}\right)=2.303 / x \times \mathrm{X}(\omega) \text {; }
$$

where, $x$ is the thickness of the sample; $I_{0}$ and $I$ are the incident and transmitted intensities, respectively. 
$\alpha=2.303(A / d)$

where, $A$ is the absorbance and $d$ is the film thickness. The absorption edges were obtained by extrapolating the linear portions of the curves to zero absorption value. It was observed that the absorption edge of PEO lies at $5.30 \mathrm{eV}$ and $4.67,4.73$, and $4.55 \mathrm{eV}$ for PEO, 1 , 3 , and $5 \mathrm{wt} \% \mathrm{CoCl}_{2}$, respectively and is also cited in Table 2 [27-30]. Furthermore, the fundamental absorption manifests itself by a rapid rise in absorption known as absorption edge, which can be used to determine the optical band gap. Insulators/ semiconductors are generally classified into two types: (a) direct band gap, and (b) indirect band gap. In direct band gap semiconductors, the top of the valence band and the bottom of the conduction band on the lie same zero crystal momentum (wave vector). If the bottom of the conduction band does not correspond to the zero crystal momentum, it is called the indirect band gap semiconductor. In the indirect band gap, materials transition from valence to conduction band should always be associated with a phonon of the right magnitude of crystal momentum. Davis and Shalliday [31] reported that near the fundamental band edge, both direct and indirect transitions occur and can be observed by plotting $\alpha^{1 / 2}$ and $\alpha^{2}$ as a function of energy (hv). The analysis of Thutpalli and Tomlin [32] is based on Eqs. (7) and (8):

$(h v n a)^{2}=C_{1}\left(h v-E_{g d}\right)$

$(h v n a)^{1 / 2}=C_{2}\left(h v-E_{g i}\right)$

where, $h v$ is the photon energy, $E_{g d}$ is the direct band gap, $E_{g i}$ is the indirect band gap, $n$ is the refractive index, $\alpha$ is the absorption coefficient, and $\mathrm{C}_{1}, \mathrm{C}_{2}$ are constants. These expressions can be applied to both direct and indirect transitions and are helpful in the determination of the band structure of materials.

When a direct band gap exists, the absorption coefficient has to subsequently depend on the energy of the incident photon [33].

$(a h v)=C\left(h v-E_{g}\right)^{1 / 2}$

where $E_{g}$ is the band gap, $C$ is a constant dependent on the specimen structure, $\alpha$ is the absorption coefficient, $v$ is the frequency of the incident light, and $h$ is Planck's constant.

The optical band gaps were evaluated from $(\alpha h v)^{2}$ and $(a h v)^{1 / 2}$ vs. hv (photon energy) plots and the allowed direct transition energies were determined by extrapolating the linear portion of the curves to zero absorption as shown in Figure $\mathbf{4 a}$ and $\mathbf{b}$. For indirect transitions, which require photon assistance, the absorption coefficient has to subsequently depend on the photon energy:

$$
\alpha h v=A\left(h v-E_{g}+E_{p}\right)^{2}+B\left(h v-E_{g}-E_{p}\right)^{2}
$$

where, $E_{p}$ is the energy of the photon associated with the transition and $A$ and $B$ are constants depending on the band structure. It is seen that optical band gaps (direct and indirect) decrease with increasing dopant weight percentage and the estimated values are cited in Table 2. These results suggest the creation of defects, disorder and/or carbon-enriched clusters due to the partial evaluation of hydrogen molecules and the
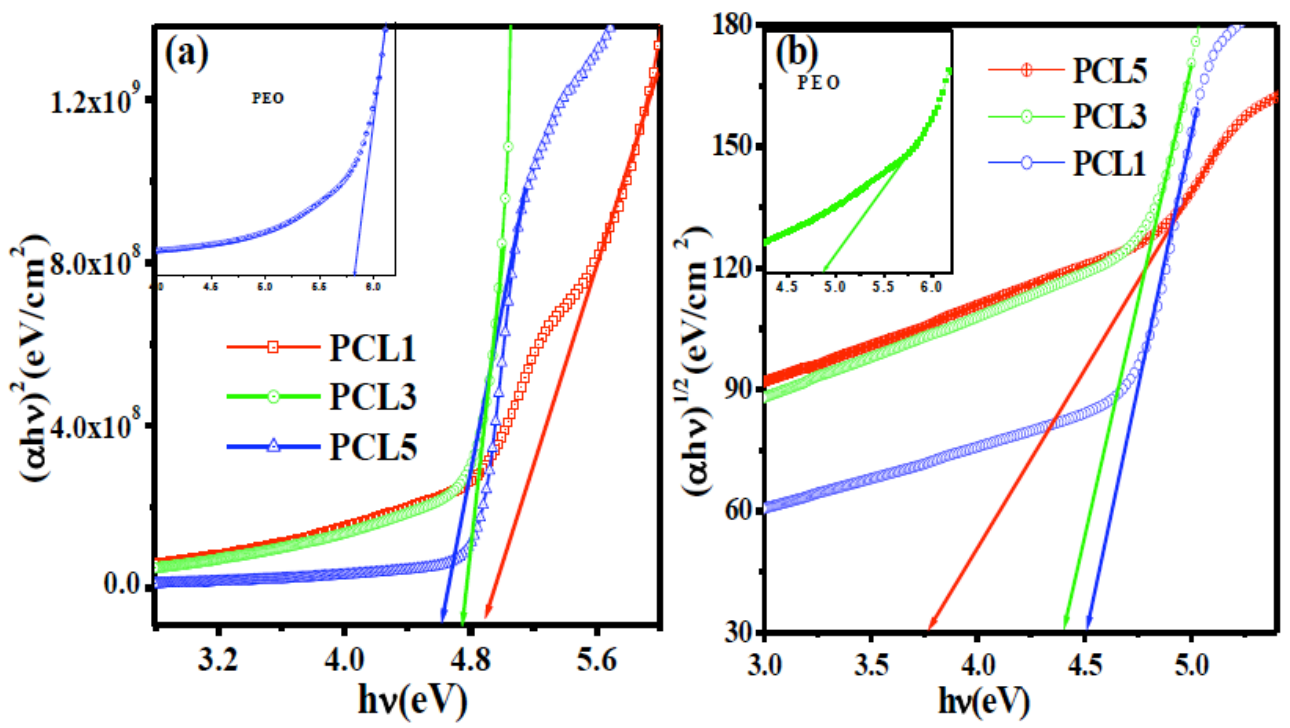

Figure 4: a) Direct and b) indirect band gaps of PEO and doped PCL films. 
formation of clusters. It can also interpret the presence of defects lead to the formation of sub-energy levels within the existing states.

To confirm this argument further, another optical parameter like activation energy was estimated using the Urbach rule, the absorption coefficient $\alpha(v)$ is described by the Urbach formula [34].

$\alpha(v)=\alpha_{\circ} \exp (h v / \Delta E)$

where, $\alpha_{0}$ is a constant and $\Delta E$ is the energy gap tail, which is interpreted as the width of the tail of the localized state of the forbidden band gap [35].

The Urbach formula in Eq. (11) was used to calculate the width of the Urbach tail of the localized states due to the defect levels in the transition gap [36]. The Urbach energy and optical band gaps show decreases with dopant weight percentage because of the structural disorder. These structural disorders produce more charge density as a result increase in the conductivity. The optical band gap (direct and indirect) and absorption edges as a function of wt\% of $\mathrm{CoCl}_{2}$ as shown in Figure 5. It is seen that band gaps and absorption edge are found to decrease due to the effect of the dopant concentration.

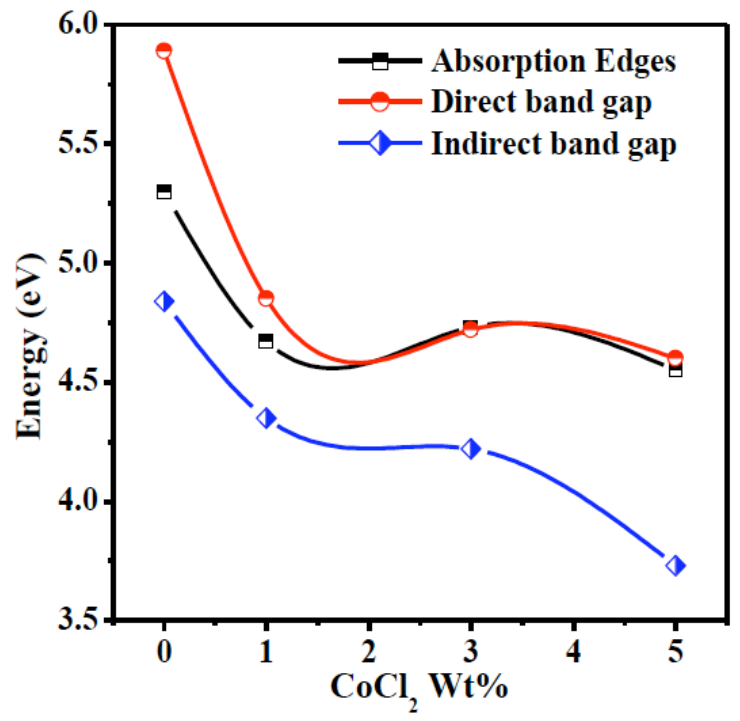

Figure 5: The dependence of optical band gaps and absorption edges on dopant Wt \%.

\section{Carbonaceous Cluster}

There is a degradation or destruction of the polymer due to chain scission and cross linking. The number of carbon atoms $(N)$ in a cluster is correlated with the optical energy band gap $\left(E_{\mathrm{g}}\right)$ determined by the Robertson relation (Robertson and O'Reilly, 1987):
$E=2 \pi \beta / \sqrt{ } \mathrm{NeV}$

where, $2 \beta$ gives the band structure energy of a pair of adjacent $\pi$ sites. The value of $\beta$ is taken to be $\sim 2.9 \mathrm{eV}$ for six numbered carbon rings as it is associated with the $\pi \rightarrow \pi^{*}$ optical transition in the $-\mathrm{C}=\mathrm{C}-$ structure [37]. The Robertson relation can be used to calculate the number of carbon atoms per cluster.

$E_{g}=34.3 / \sqrt{ }(N)$ eV

where, $\mathrm{N}$ is the number of carbon atoms per conjugation length for PEO and doped polymer electrolytes.

From the table it is seen that the number of carbon atoms in the cluster increases with the increasing dopant is attributed to the breakage of energetic electrons, i.e. $\mathrm{C}-\mathrm{H}$ bond as a result release of hydrogen [38]. Thus, it can be inferred that any change in the optical properties of the polymers is basically due to the electron energy loss [39]. This is confirmed from the obtained FT-IR result.

\section{Differential Scanning Calorimetry (DSC) Study}

DSC measurement was used to determine the melting temperature $\left(T_{m}\right)$, glass transition temperature $\left(T_{g}\right)$, and relative crystallinity $\left(X_{c}\right)$ of polymer electrolytes. Figure 6 shows the sharp endothermic peak observed that was assigned to the melting temperature of PEO at $67^{\circ} \mathrm{C}$ have been decreased to $54.4^{\circ} \mathrm{C}$ for $5 \mathrm{wt} \%$. The decrease in $\mathrm{T}_{\mathrm{m}}$ might be related to a decrease in the crystallinity of the film. The endothermic curves also indicate a reduction in PEO crystallinity. The study of the degree of crystallinity is very significant one to understand the change in the thermal characteristics induced by $\mathrm{CoCl}_{2}$. The relative percentage of crystallinity $X_{c}$ has been calculated using Equation (14).

$X_{C}=\left(\frac{\Delta H_{m}}{\Delta H_{m}^{0}}\right) 100 \%$

where $\Delta H_{\mathrm{m}}$ and $\Delta H^{0}{ }_{\mathrm{m}}$ are the enthalpy of melting of the sample and the enthalpy of melting of a $100 \%$ pure crystalline PEO, respectively. $\Delta H^{0}{ }_{\mathrm{m}}=220.81 \mathrm{~J} / \mathrm{g}$ [40]. The values of $T_{g}, T m, \Delta H_{m}$ and $X_{c}$ are summarized in Table 3.

The degree of crystallinity of the polymer electrolyte decreases with wt\% of the salt, which causes an increase in the amorphous phase. It means the polymeric chains are more flexible in the amorphous 
Table 2: The Variation of Optical Band Gap Energy, Number of Carbon Atoms (N) Per Conjugated Length and Urbach Energy (eV) of PEO and PCL Films

\begin{tabular}{|c|c|c|c|c|c|}
\hline \multirow{2}{*}{ Sample } & \multicolumn{2}{|c|}{ Optical band gaps(eV) } & Absorption Edges(eV) & Urbach energy(eV) & $\begin{array}{c}\text { Number of carbon } \\
\text { atoms(N) }\end{array}$ \\
\cline { 2 - 6 } & Direct & Indirect & 4.84 & 5.30 & 0.99 \\
2.5 \\
\hline \hline PEO & 5.89 & 4.35 & 4.67 & 0.90 & 2.7 \\
\hline PCL1 & 4.85 & 4.22 & 4.73 & 0.71 & 2.8 \\
\hline PCL3 & 4.72 & 3.73 & 4.55 & 0.21 & 2.9 \\
\hline
\end{tabular}
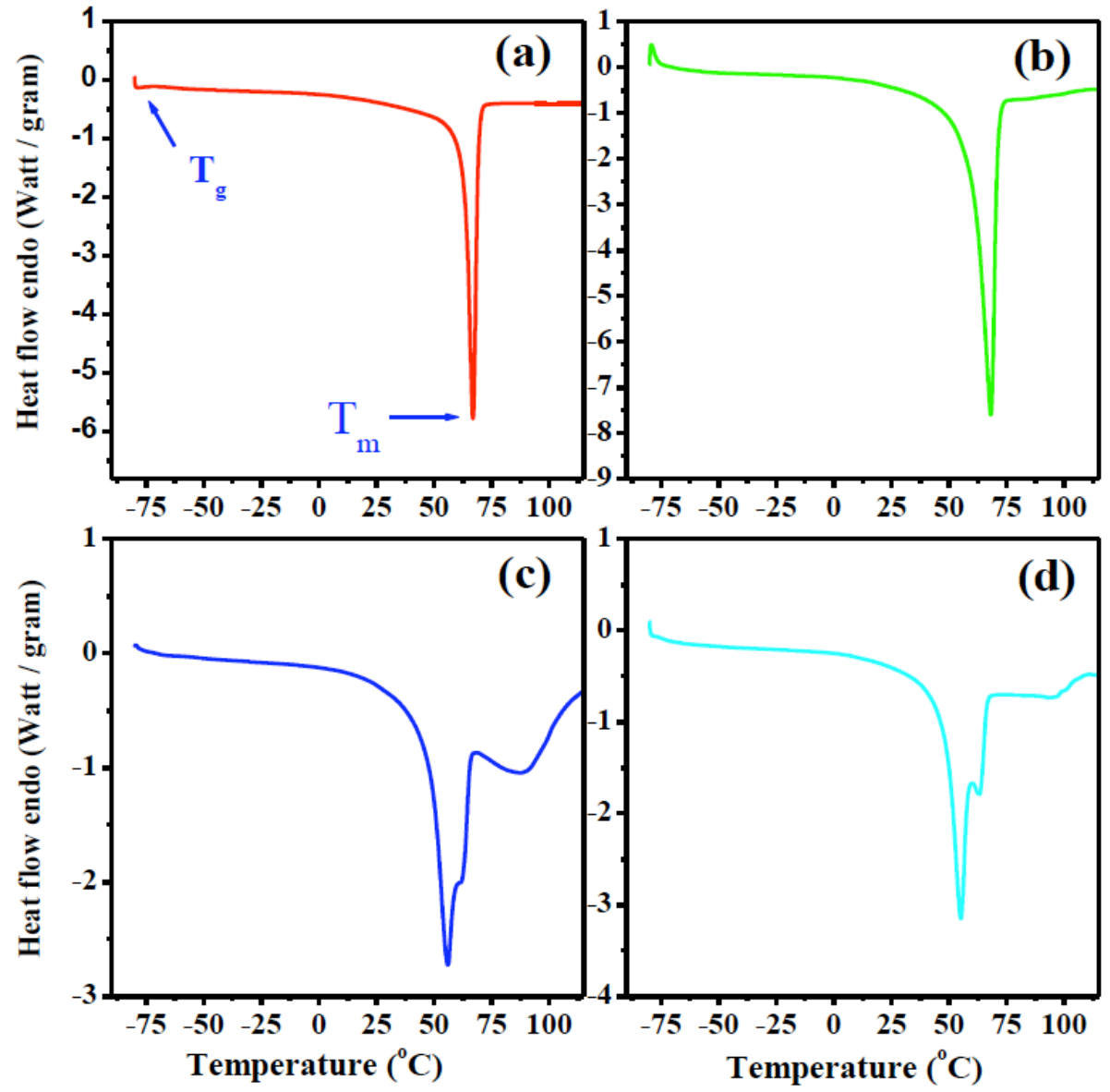

Figure 6: DSC curves of polymer electrolytes at various wt\% of $\mathrm{CoCl}_{2}$ (a) 0 ; (b) 1 ; (c) 3 ; (d) 5 .

phase as a result of the enhancement of segmental motion, thus raising the conductivity. The reduction of $T_{m}$ and $X_{c}$ suggests that the interaction between the polymer host backbone and $\mathrm{CoCl}_{2}$ affects the main chain dynamics of the polymer. This is due to the interaction between the oxygen group of ether units of PEO and $\mathrm{Co}^{2+}$ ions, where $\mathrm{Co}^{2+}$ ions interrupt the packing of PEO molecules and decrease the degree of crystallinity.

Table 3 shows the variation of melting enthalpy and the degree of crystallinity as a function of the doping levels. Apparently, the value of melting enthalpy decreases gradually with increasing $\mathrm{CoCl}_{2}$ content, indicating a decrease in crystallinity. All the results indicate that $\mathrm{CoCl}_{2}$ is dispersed in the crystalline regions of the bulk of PEO matrix which undergo alteration in the crystalline arrangement of the PEO as a result increase in the amorphous region. These results are well agreed with the XRD result [41]. The glass transition temperature $\left(T_{g}\right)$ involves the freezing of large scale molecular motion without change in the structure at which the glassy phase of the sample becomes a rubbery amorphous phase upon heating. 
Table 3: Thermal Properties of Polymer Electrolytes Films

\begin{tabular}{|c|c|c|c|c|}
\hline Sample & $\mathbf{T}_{\mathbf{g}}\left({ }^{\circ} \mathbf{C}\right)$ & $\mathbf{T}_{\mathbf{m}}\left({ }^{\circ} \mathbf{C}\right)$ & $\Delta \mathbf{H}_{\mathrm{m}}\left(\mathbf{J g}^{-1}\right)$ & 193.9 \\
\hline \hline PEO & -80.02 & 67.0 & 185.5 & 87.81 \\
\hline PCL1 & -76.04 & 68.6 & 134.2 & 64.00 \\
\hline PCL3 & -71.24 & 56.1 & 54.6 & 24.73 \\
\hline PCL5 & -68.06 & 54.4 & $\mathbf{X}_{\mathbf{c}}(\%)$ & \\
\hline
\end{tabular}

The variation of $T_{g}$ may be concerned with the mobility of the polymer chain, for lower $T_{g}$ usually leads to easier chain relaxation. In PEO-based polymeric electrolytes; cobalt ion promote the conduction by segmental motion in the amorphous phase and the corresponding $T_{g}$ values are cited in Table 3. A polymer electrolyte with low $\mathrm{T}_{\mathrm{g}}$ always implies fast ion conduction [42].

\section{Thermo Gravimetric Analysis (TGA) / Differential Thermogram (DTG) Studies}

This study gives the thermal stability, phase transitions and crystallization of the polymer electrolytes was employed using TGA-DTG, it traces of all the polymer electrolyte films are shown in Figure 7 (a-d).

\section{Fluorescence Spectra}

This study gives the strong emission at particular wavelength of material and Figure 8 (a-d) gives the fluorescence emission spectra of PEO and PCL films. For PEO shows broad emission in the range of 250$500 \mathrm{~nm}$ with a peak at $359 \mathrm{~nm}$ in Figure $8 \mathbf{a}$.

In general, the excitation of PEO and PEO doped in the range of $210-236 \mathrm{~nm}$, for $1 \% \mathrm{CoCl}_{2}$ the broad
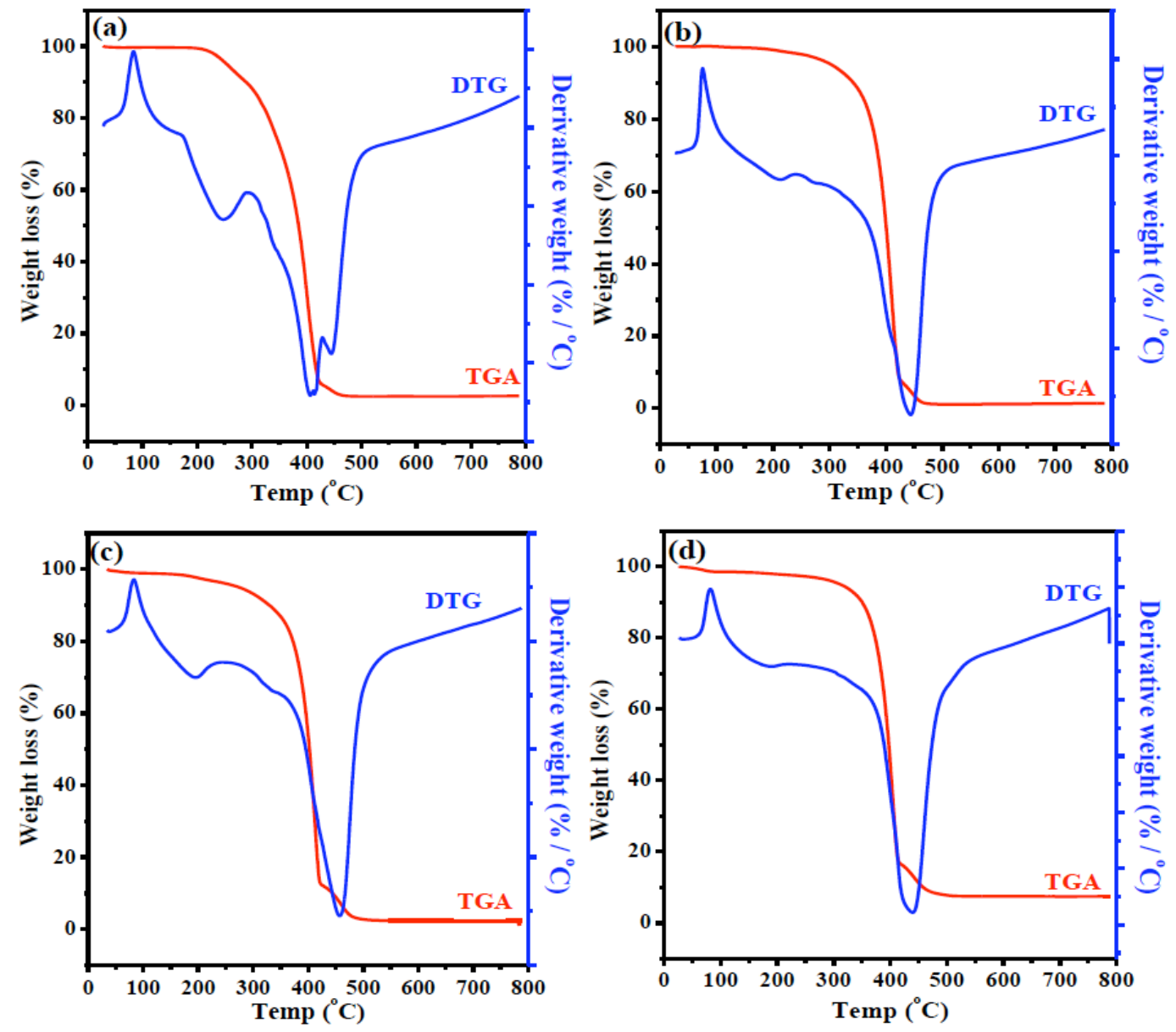

Figure 7: TGA-DTG curves of polymer electrolytes at various wt\% of $\mathrm{CoCl}_{2}$ (a) 0 ; (b) 1 ; (c) 3 ; (d) 5 . 
Table 4: Initial and Decomposition Temperatures and Percentage of Total Weight Loss for Various PCI Films

\begin{tabular}{|c|c|c|c|c|c|}
\hline Sample & $\begin{array}{c}\text { Initial Weight } \\
\text { Loss Temperature }\end{array}$ & Weight Loss & $\begin{array}{c}\text { Decomposition } \\
\text { Temperature }\end{array}$ & $\begin{array}{c}\text { Weight Loss } \\
\text { Loss }\end{array}$ & (\%) \\
\hline \hline PEO & $\left({ }^{\circ} \mathbf{C}\right)$ & $(\%)$ & 284 & 87.85 & 96.79 \\
\hline PCL1 & 32 & 8.94 & 328 & 90.46 & 98.83 \\
\hline PCL3 & 54 & 8.36 & 361 & 83.3 & 97.14 \\
\hline PCL5 & 79 & 13.84 & 413 & 82.83 & 91.16 \\
\hline
\end{tabular}
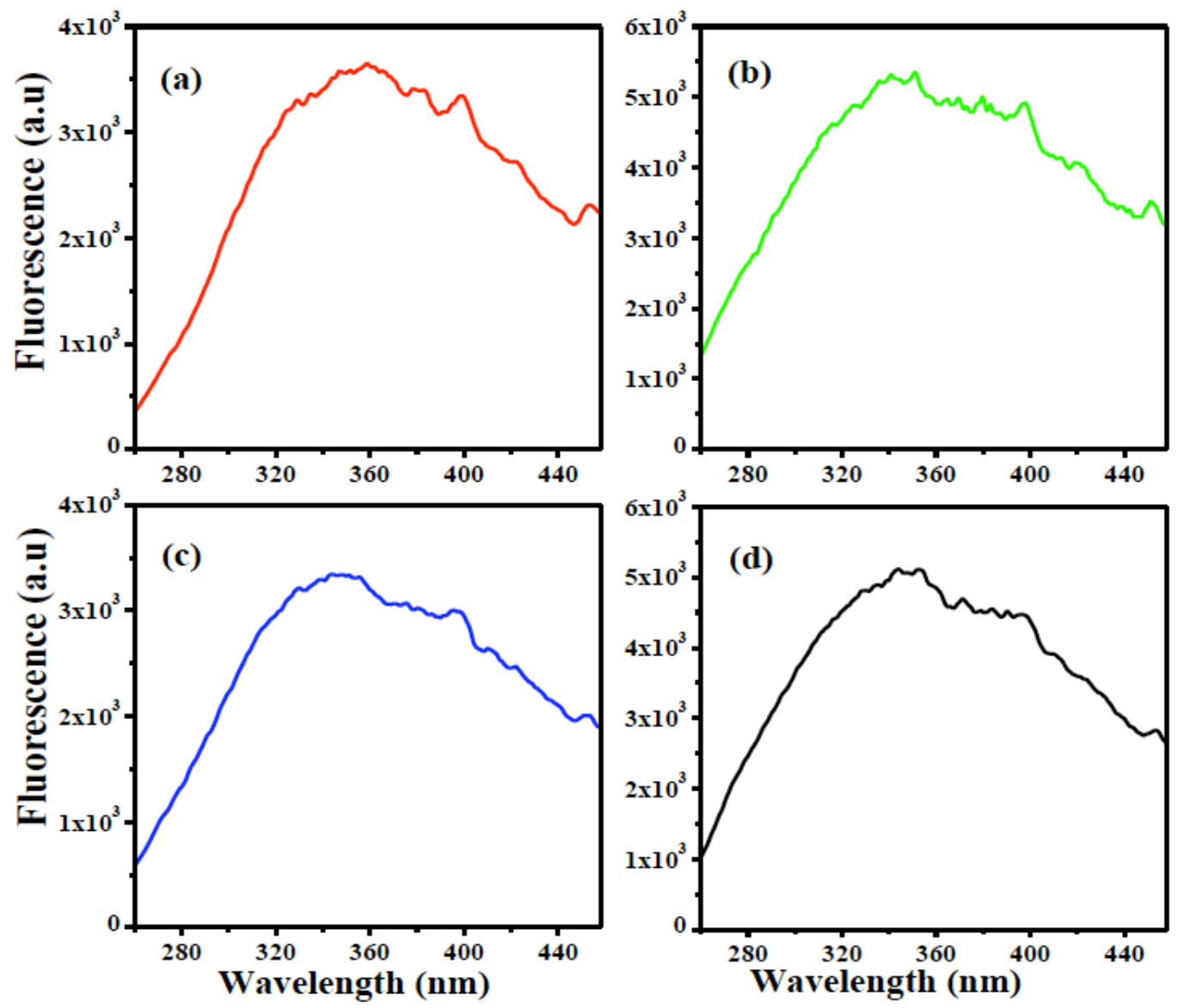

Figure 8: Fluorescence spectra of polymer electrolytes at various wt\% of $\mathrm{CoCl}_{2}$ (a) 0 , (b) 1, (c) 3 , (d) 5 .

emission of 250-446nm with peaks at 350,367 , and $485 \mathrm{~nm}$ in Figure $\mathbf{8 b}$ and with $3 \% \mathrm{CoCl}_{2}$ broad emission of $260-446 \mathrm{~nm}$ with a peak at 351 and $475 \mathrm{~nm}$ in Figure 8c. PEO doped with $5 \% \mathrm{CoCl}_{2}$ broad emission of 250 $446 \mathrm{~nm}$ with a peak at 352,371 and $390 \mathrm{~nm}$ in Figure 8d. Since the intrinsic PEO polymer has no fluorescence, according to the excitonic luminous mechanism, we conclude that the luminescence comes from the electronic transition between exciton band (produced due to the doping) and valence band [43]. Obviously, the PEO molecule synthesized has conjugated transitions; moreover, the rigidity and co planarity of the
PEO molecule has been improved. As the salt concentration increases the intensity of the fluorescence spectra also increases suggesting that transition is dominating it may suitable for some potential applications in organic optoelectronics.

\section{CONCLUSIONS}

Polymer electrolytes PEO: $\mathrm{CoCl}_{2}$ with different compositions has been prepared using the solution cast technique. SEM results are well correlated; phase change from crystalline to amorphous as well agrees 
with the obtained XRD. The optical absorption showed a blue (hypsochromic, $\mathrm{n} \rightarrow \pi^{*}$ transition) shift towards the intensive region of the solar spectra in the visible range. Optical absorption edge and optical band gaps (direct and indirect) showed a decreasing trend with increased concentration of the dopant. These data suggest that the present electrolyte system is a worthy candidate for electrochemical device applications.

DSC measurements affirm that doping of $\mathrm{CoCl}_{2}$ into PEO polymer electrolyte could suppress the crystallinity of polymer electrolyte and enhanced the amorphous reason. TGA-DTG analysis suggests that the thermal stability of the composites is higher than that of the PEO. This enhanced thermal stability of the composites has also ascribed to the interaction between PEO and $\mathrm{CoCl}_{2}$. With these attractive properties have many potential applications in various fields. Thus, it can be infer that the introduction of ether backbone to other precursor polymer would significantly improve the film-forming properties and hold promise for the design of a new generation of optoelectronic materials, applications in optical devices, solid-state batteries and other energy storage.

\section{ACKNOWLEDGEMENTS}

The financial support for the work under the UGCNew Delhi, India for sanctioning the research project (Letter F.No.41-879/2012/SR dated 25-07-12) is greatly acknowledged. The DSC facilities from USIC, Mangalore University is gratefully acknowledged.

\section{REFERENCES}

[1] Subba Reddy Ch.V, Sharma AK, Narasimha Rao VVR. Polymer 2009; 47: 1318.

[2] Ravi M, Kiran Kumar K, Madhu Mohan V, Narasimha Rao VVR. Polymer Testing 2014; 33: 152. http://dx.doi.org/10.1016/i.polymertesting.2013.12.002

[3] Reddeppa N, Reddy CVS, Achari VBS, Narasimha Rao VVR, Sharma AK. Ionics 2009; 15: 255. http://dx.doi.org/10.1007/s11581-008-0269-1

[4] Turky G, Dawy M. Materials Chemistry and Physics 2002; 77: 48.

http://dx.doi.org/10.1016/S0254-0584(01)00574-0

[5] Onoda M, Manada Y, Moritn S, Yoshino K. Journal of Physical Society of Japan 1989; 58: 1985.

http://dx.doi.org/10.1143/JPSJ.58.1895

[6] Tabatn M, Satoh M, Kanoto K, Yoshiro K. Journal of Physical Society of Japan 1986; 55: 1305.

http://dx.doi.org/10.1143/JPSJ.55.1305

[7] Proneanu S, Toren R, Brie M, Mihilesan G. Materials Science Forum 1995; 191: 241.

http://dx.doi.org/10.4028/www.scientific.net/MSF.191.241

[8] Sundar M, Selladurri S. Ionics 2006; 12: 281

http://dx.doi.org/10.1007/s11581-006-0048-9
Lee JK, Lee YJ, Chae WS, Sung YM. Journal of Electroceramics 1997; 17: 941.

http://dx.doi.org/10.1007/s10832-006-7672-7

[10] Uma Devi C, Sharma AK, Narasimha Rao VVR. Materials Letters 2002; 56: 167.

http://dx.doi.org/10.1016/S0167-577X(02)00434-2

[11] Subba Reddy ChV, Sharma AK, Narasimha Rao VVR. Journal of Materials Science Letters 2002; 21: 105. http://dx.doi.org/10.1023/A:1014276611225

[12] Subba Reddy ChV, Sharma AK, Narasimha Rao VVR Journal of Power Sources 2002; 111: 357.

[13] Lakshmi Narayana K. Ph D Thesis, SV University 1995.

[14] Staryga E, Swiatek J. Thin Solid Films 1979; 56: 311. http://dx.doi.org/10.1016/0040-6090(79)90132-9

[15] Bahri R, Singh HP. Thin Solid Films 1980; 69: 281. http://dx.doi.org/10.1016/0040-6090(80)90578-7

[16] Obreja P, Kusko M, Cristea D, Purica M. Proceeding of the Symposium on Photonics Technologies for Framework Program 2006; 392.

[17] Faim TD. Proceedings of SPIE 2004; 5250: 423. http://dx.doi.org/10.1117/12.513363

[18] Ravi M, Pavani Y, Kiran Kumar K, Bhavani S, Sharma AK, Narasimha Rao VVR. Materials Chemistry and Physics 2011; 130: 442. http://dx.doi.org/10.1016/j.matchemphys.2011.07.006

[19] Ulanski J, Polanowski P, Traiez A, Hofmann M, Dormann E. Synthetic Metals 1998; 94: 23. http://dx.doi.org/10.1016/S0379-6779(97)04133-7

[20] Subramanya K, Raghu S, Devendrappa H. AIP Conf Proc 2012; 1447: 965.

[21] Saumya RM, Awalendra K, Thakur, Chaudhary RNP. Ionics 2008; 14: 255.

[22] Katharina M, Picker-Freyer. Journal of Thermal Analysis and Calorimetry 2006; 85(2): 495.

[23] Reddy MJ, Chu PP. Electrchim Acta 2002; 47: 1189. http://dx.doi.org/10.1016/S0013-4686(01)00846-5

[24] Halder B, Singru RM, Maurya KK, Chandra S. Phys Rev B 1996; 54: 7143.

http://dx.doi.org/10.1103/PhysRevB.54.7143

[25] Al-Faleh RS, Zihlif AM. Physica B 2011; 406: 1919. http://dx.doi.org/10.1016/j.physb.2011.01.076

[26] Suriani Ibrahim, Roslina Ahmad. Journal of Luminescence 2012; $132: 147$. http://dx.doi.org/10.1016/j.jumin.2011.08.004

[27] Zajak H. Optics, Addison Wesley, London 1975; 85.

[28] Elliot S. The Physics Chemistry of Solids, John Wiley, New York 1998; 225: 392

[29] Abu-Jamous A, Zihlif AM. Physica B 2010; 405: 2762. http://dx.doi.org/10.1016/j.physb.2010.02.050

[30] Davis E, Mott N. Philos Mag 1970; 22: 179. http://dx.doi.org/10.1080/14786437008221061

[31] Davis DS, Shalliday JS. Phys Rev 1960; 118: 1020. http://dx.doi.org/10.1103/PhysRev.118.1020

[32] Thutulpalli GM, Tomlin SG. J Phys D: Appl Phys 1976; 9: 1639.

http://dx.doi.org/10.1088/0022-3727/9/11/010

[33] Subba Reddy ChV, Sharma AK, Narasimha Rao VVR. Journal of Materials Science Letters 2002; 21: 105.

http://dx.doi.org/10.1023/A:1014276611225

[34] Urbach F. Phys Rev 1953; 92: 1324. http://dx.doi.org/10.1103/PhysRev.92.1324

[35] Zidan HM, Abu-Elnader M. Physica B 200; 355: 308.

[36] Raja V, Sharma AK, Narasimha Rao VVR. Mater Lett 2003; 57: 4678 . http://dx.doi.org/10.1016/S0167-577X(03)00384-7 
[37] Phukan T, Kanjilal D, Goswami TD, Das HL. Radiat Meas B 2003; 36: 611.

[38] Abdul-Kader AM, Turos A, Jagielski J, Nowicki L, Ratajczak R, Stonert A, Al-Madeed M. 2005; 78: 281.

[39] Vijay Kumar, Sonkawade RG. Radiation Physics and Chemistry 2012; 81: 652.

http://dx.doi.org/10.1016/j.radphyschem.2012.02.027
[40] Braun W, Hellwege KH, Knappe W, Kolid-Z UZ. Polymer 1967; 215: 10.

[41] Abdelaziz M. Physica B 2011; 406: 1300. http://dx.doi.org/10.1016/j.physb.2011.01.021

[42] Suriani Ibrahim, Mohd Rafie Johan. Int J Electrochem Sci 2012; 7: 2596.

[43] Wang SG, He H, Cui X J, Gong J, Qu LY. Acta Chimica 2001; 59(8): 1163. 